Marjana Šifrar Kalan

Universidad de Ljubljana

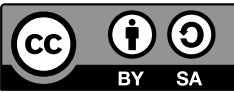

Lucija Šarc

Ljubljana

\title{
La presencia de la literatura española e hispanoamericana en los institutos de educación secundaria eslovena a partir del año 1945
}

Palabras clave: literatura española, literatura hispanoamericana, instituto de educación secundaria en Eslovenia, plan curricular esloveno, libro del alumno de literatura mundial, clase de literatura

\section{Introducción}

El objetivo de este artículo es analizar la recurrencia de los textos literarios españoles e hispanoamericanos en las clases de literatura (de esloveno) ${ }^{1}$ en los Institutos de Educación Secundaria eslovena basándose en los currículos escolares y en los libros del alumno en el periodo entre el año 1945 hasta la actualidad. Por lo tanto, cabe destacar que nos referimos a dos realidades sociopolíticas diferentes: a Yugoslavia (1945-1991), cuando Eslovenia era una de las seis repúblicas, y a Eslovenia (1991-), un país que se independizó de Yugoslavia. En ambas realidades el contexto sociopolítico jugará un gran papel.

La enseñanza de la literatura resulta muy sensible a los cambios producidos en los mecanismos de producción cultural y de cohesión social de los distintos momentos históricos. Ello se debe a que la literatura se sitúa en el campo de la representación social,

1 La clase de esloveno en cualquier programa de escuela secundaria se compone de lengua eslovena y de literaturas eslovena y mundial. 
refleja y configura valores e ideología, y participa en la forma de institucionalizarse la cultura a través de la construcción del imaginario colectivo. El modelo educativo adoptado responde, así, en primer lugar, a la función que cada sociedad atribuye a la literatura. Esta función se corresponde con la determinación de unos contenidos docentes, de una selección de textos y de unas prácticas de enseñanza en el aula. (Colomer, 2010)

Se examina la presencia de estas literaturas de 1945 a $2017^{2}$ para advertir algunas insuficiencias de la selección y tratamiento de las literaturas analizadas. En otras palabras, nos interesa saber qué autores y qué textos literarios escritos en español conocen los alumnos que a los 19 años terminan los cuatro años de educación en "gimnazija", la escuela secundaria que prepara a los adolescentes para sus futuros estudios universitarios, o sea, los futuros intelectuales, para quienes se supone que toman la literatura como uno de sus valores.

Los currículos escolares en las clases de literatura en los institutos eslovenos además de literatura eslovena obligan también la enseñanza de la literatura mundial, que incluye las literaturas española e hispanoamericana. El criterio principal de la selección de obras literarias es, según la profesora eslovena de Didáctica de la Literatura Krakar Vogel (2004: 64-65) y muchos otros expertos en enseñanza de literatura, el canon mundial, pero es imposible dar respuesta a la cuestión de qué obras pertenecen a ese canon y cuáles se pueden omitir. Recurrimos aquí a uno de los muchos intentos de respuesta de Cerrillo Torremocha (2013: 24):

Todo canon debiera estar formado por obras y autores que, con dimensión y carácter históricos, se consideran modelos por su calidad literaria y por su capacidad de supervivencia y trascendencia al tiempo en que vivieron, es decir textos clásicos. Pero, junto a ellos, pueden incluirse en un canon otros libros, de indiscutible calidad literaria, que no hayan alcanzado esa dimensión de "clásicos" porque no ha pasado aún el tiempo necesario para que sea posible ese logro.

La polémica es muy actual, y, según Kopczky (2008: 339-340), presenta dilemas conectados con el canon en el ámbito escolar: (1) un canon para todos o para la élite y otros miembros de la sociedad, (2) énfasis en el pasado o en la actualidad, (3) libertad de selección de la lectura o lectura obligatoria, (4) el

2 Para el año escolar 2017-18 queda en vigor el currículo que se certificó en 2008. Desde entonces no se han hecho cambios. 
punto de vista pragmático o la experiencia estética, (5) refuerzo de la identidad nacional o europea?

Jožef Beg (2013) en su análisis de toda la literatura mundial en los libros del alumno de IES eslovenos declara que la selección de la literatura mundial se puede igualar con el canon occidental compuesto de los grandes autores de la literatura universal ${ }^{3}$. Las razones son las siguientes: el capital de lengua y cultura, el reconocimiento de naciones grandes y los criterios literarios. La autora detecta los cambios en el canon de las literaturas de los siglos XIX y XX y las deficiencias sobre todo en la literatura contemporánea, en los textos dramáticos y la omisión de autoras, tanto en el canon mundial como en el nacional.

Hispanistas eslovenas que ya han criticado la escasa selección de las literaturas española e hispanoamericana son Kalenić Ramšak (2011a) y Pregelj (2008). Kalenić Ramšak analiza la enseñanza de literatura del último plan curricular (Učni načrt za slovenččino: gimnazija, 2008) y concluye que la literatura en español presenta una deficiencia, ya que se menciona escasa y a veces inadecuadamente dentro del contexto de la historia literaria, como, por ejemplo, en el caso del romance español que se menciona en la literatura del s. XX y no del s. XIX, aunque se sabe que la forma fue usada ya por el poeta esloveno Prešeren en el s. XIX (1800-1848); la omisión de la influencia de los árabes en la literatura medieval; la omisión de obras de teatro y lírica del Siglo de Oro, etc. (2011a: 235-238). Pregelj (2008) se dedica a analizar la literatura española en tres libros de lectura (Svet književnosti, Branja, Zlati poljub, Poljub zlata), sobre todo desde el punto de vista de la traducción y de la interpretación, como en el caso de la poesía de García Lorca. Concluye que la literatura española se encuentra en una posición subestimada en comparación con la literatura italiana, la inglesa o la francesa, y que hace falta la participación en la interpretación de algún experto de literatura española. Sin embargo, Žbogar (2015: 119) observa que el porcentaje de los textos de la literatura mundial en general ha aumentado un $10 \%$ comparando el plan curricular (2008) vigente hasta el momento actual y el del año 1998, y añade que el plan curricular esloveno actual es comparable a los curriculos europeos más progresista, ya que aspira

3 Homero (La Iliada y La Odisea), Sófocles (Edipo rey, Antígona), Alighieri (Divina comedia), Boccaccio (Decamerón), Shakespeare (Hamlet, Romeo y Julieta), Molière (Tartufo), Goethe (Las cuidas del joven Werther), Byron (Las peregrinaciones de Childe Harold), Pushkin (Eugenio Oneguin), Dostoievski (Crimen y castigo), Tolstoi (Guerra y paz), Zola (L’Assommoir), Baudelaire (lírica), García Lorca (lírica), Kafka (La metamorfosis), Joyce (Ulises), Proust (Por el camino de Swann) y Camus (El extranjero). 
al desarrollo de las competencias culturares y pluriculturales, refuerzo de la identidad cultural y conocimiento de diferentes saberes (Žbogar, 2015: 121).

El plan curricular del esloveno determina que la clase de literatura está destinada para la enseñanza de un lector educado, futuro erudito. Se trata del lector que en su reflexión de la literatura incluye las experiencias de otras lecturas, los conocimientos de los fenómenos literarios y el saber general cultural. Entiende la literatura como la parte de la cultura en un determinado tiempo, en un espacio pluri y supra nacional, como un fenómeno que configura el sistema de valores del individuo y de la sociedad (2008: 42). Aparte de la competencia literaria, el lector debería mostrar una competencia comunicativa desarrollada, el conocimiento del sistema de los fenómenos literarios, textos, circunstancias literarias, históricas y culturales, la competencia de poder extender los conocimientos de la literatura y su clasificación en el contexto cultural y la competencia TIC 4 (Žbogar, 2013: 19-20). Estos objetivos del plan curricular (2008) coinciden con los que se proponen en el documento europeo sobre la enseñanza de literatura a los adolescentes europeos Literary Framework for Teachers in Secondary Education (2012).

\section{La selección de literatura en español según los Planes curriculares nacionales}

La enseñanza está siempre condicionada con el espacio y el tiempo en el cual transcurre. El plan curricular es el documento oficial del estado que varía en el contenido, los objetivos, la metodología y la organización dependiendo de la sistematización y racionalidad de la enseñanza (Klemenčič y Štrempfl, 2011: 70). Los publica el Ministerio de Educación, Deporte y Ciencia (Ministrstvo Republike Slovenije za izobraževanje, znanost in šport) en colaboración con la Consejería de Educación (Zavod Republike Slovenije za šolstvo). Los redactan los miembros del comité, expertos en la asignatura - los consejeros, los profesores practicantes y los profesores universitarios. Desde 1945 se han publicado 11 planes curriculares que modificaron la enseñanza de la Lengua y Literatura ${ }^{5}$ en enseñanza secundaria, de los cuales tres (1962, 1964 y 1975) son idénticos. El análisis de estos documentos trata de encontrar también las razones para la selección de las obras literarias españolas e hispanoamericanas basándose en las traducciones y otras influencias que las obras tuvieron en el ámbito literario esloveno.

4 Tecnologías de la Información y la Comunicación.

5 La asignatura simplemente siempre se ha llamado esloveno (slovenščina). 
En los primeros tres años después de la guerra se publicaron tres planes curriculares (1945, 1946 y 1947). En todos ellos se puede notar el énfasis en las literaturas eslovena, serbia y croata, lo que es indudable teniendo en cuenta las circunstancias sociales y políticas. Las autoridades querían educar a los jóvenes principalmente hacia el respeto de la patria y la Unión Soviética. El objetivo de la asignatura fue obviamente muy ideológico como se puede ver en esta cita del plan curricular del año $1946^{6}$ :

[...] naj vzgoji ob domačih in tujih tekstih in zgledih, zlasti ob narodno osvobodilni borbi in ob prizadevanjih ob času obnove mladi rod $\mathrm{v}$ dejavni ljubezni do domovine, do slovenskega ljudstva, do vseh narodov Jugoslavije, do velike Sovjetske zveze in do vsega naprednega človeštva (1946: 8).

Según los tres planes curriculares la lectura obligatoria fue Cervantes, pero su obra Don Quijote es citada solo en el plan del 1947 que no solo representa una lectura en casa por parte del alumno sino que se prevé el análisis de ciertos fragmentos en clase ${ }^{7}$. En los primeros dos planes curriculares aparece Calderón de la Barca sin citar sus obras. Probablemente se refería a las obras El alcalde de Zalamea o El gran teatro del mundo que eran hasta entonces las únicas traducidas al esloveno (Oton Zupančič, 1912 y Janko Moder, 1942), porque La vida es sueño se publicó en una traducción eslovena de 1969 (Pregelj, 2005: 46). El único autor hispanoamericano que figuraba era Neruda que está clasificado bajo la prosa y lírica mundial desde el siglo XIX. Su poesía y comentarios aparecen en fragmentos en varias revistas, la primera vez en el año 1934 (Šumrada, 2015: 7, 19). pero será en 1975 cuando se publique su monografía Izbrane pesmi (Poesía seleccionada). Sorprende la aparición de Vicente Blasco Ibáñez, autor del naturalismo español, ya que no es parte del canon estableci$\mathrm{do}^{8}$ de la literatura mundial.

También el plan curricular de 1948, que contiene solo a Don Quijote, surgió de los planes curriculares yugoslavos pero haciendo especial énfasis en la lengua

6 «[...] que forme con los textos nacionales y extranjeros, con ejemplos, sobre todo con la lucha de liberación nacional y con los esfuerzos en el periodo de reconstrucción a la generación joven en amor activo hacia la patria, hacia el pueblo esloveno, hacia todas las naciones yugoslavas, hacia la gran Unión Soviética y hacia toda la humanidad progresista». (La traducción es nuestra).

$7 \quad$ Las primeras partes de Don Quijote fueron traducidas en 1864 por Fran Zakrajšek. En 1890 se publicó la traducción adaptada para los jóvenes por Fran Nedelko. La traducción de la obra entera realizada por Stanko Leben fue publicada en 1935 (Kalenić Ramšak, 2011b: 411-412).

8 Su obra ha sido omitida hasta en algunas historias literarias, ej. Jiménez y Cáceres: Historia esencial de la literatura española e bispanoamericana, 2008. 
y literatura eslovenas, según consta escrito en el mismo plan (1948: 36). Sin embargo, en el plan se puede comprobar que la literatura después de la primera guerra mundial, a donde pertenece Neruda, menciona autores rusos exclusivamente.

El plan curricular de 1955 sigue con el objetivo de educar a los jóvenes en el respeto al socialismo y sus valores, por lo tanto prevalecen los autores yugoslavos, y el porcentaje de los autores de la literatura mundial es más bajo que en los planes anteriores; también el de la literatura española e hispanoamericana ya que aparece solo Cervantes. La obra que se cita no es su famosa novela sino una novela biográfica sobre la vida de Cervantes de un autor alemán ${ }^{9}$, lo que significa que no podemos encontrar ninguna obra en la lengua castellana.

Los materiales docentes (1962 y 1964) se convirtieron en el plan curricular oficial en 1975 y allí se determina la presencia de los más importantes representantes de la literatura mundial y sus obras, así se delimita un autor de la literatura española (Cervantes) y un autor de literatura hispanoamericana (Neruda). Es la primera vez que el plan sugiere el tratamiento de literaturas geográficamente alejadas, entre ellas la hispanoamericana, además de literatura árabe, china, japonesa y africana.

Como fruto de las reformas en los años 80, en 1986 se publica y confirma un nuevo plan curricular que sigue las nuevas tendencias socialistas en la educación en toda Yugoslavia - el elitismo de los institutos (gimnazija) fue atenuado, ya que la enseñanza empezó a igualarse para todo tipo de escuelas secundarias. El tratamiento de la literatura mundial en las clases de literatura obtuvo más importancia, lo que es posible conectar con el cambio de los valores que ya no daban énfasis en la literatura que proporcionaba los valores del socialismo, sino en la selección por los criterios del canon y significado artístico. Aparte de Cervantes gana su puesto entre la literatura obligatoria F. García Lorca (Canción de jinete), mientras que la novela Cien años de soledad de G. García Márquez y la prosa corta de J. L. Borges figuran en las obras optativas. La inclusión muy tardía de García Lorca no quiere decir que los eslovenos no conocieran antes su obra; de hecho se presenta con otros poetas españoles en una revista literaria eslovena (Ljubljanski zvon) en 1932 (Pregelj y Kozak, 2007: 551) y las primeras traducciones de su poesía se publican en 1947, y la primera monografía en 1958 (Pregelj, 2006: 1092). Cuatro obras de teatro de Lorca se presentaron en los teatros eslovenos entre 1950 y 1962: La Casa de Bernarda Alba fue la primera (Pregelj y Kozak, 2007: 554).

9 Frank, B. (1934): Cervantes. Amsterdam: Querido Verlag. 
Con la independencia de Eslovenia en 1991 cambiaron también las tendencias en la enseñanza. El plan curricular de 1992 cancela el apartado de las literaturas yugoslavas. La selección de autores y obras mundiales no cambia mucho (pero los contenidos se dividen entre los obligatorios y optativos), porque ya en el último plan curricular se respeta el criterio del canon. El único cambio en el área de la literatura hispanoamericana es que Borges y su cuento corto $E l$ fin figuran entre la literatura obligatoria, hecho que no sorprende debido a la gran influencia de este autor en la literatura mundial y eslovena. Después de 1992 cambian bastante la metodología para el trabajo con los textos literarios (Kos et al., 1994), ya que con cada obra se introducen los elementos para la interpretación. Por ejemplo, al tratar Don Quijote, los elementos necesarios son las informaciones de la novela caballeresca, los aspectos teóricos del género literario de la novela, la comparación de los personajes (don Quijote y Sancho Panza), el idealismo, el realismo y lo tragicómico. Los cambios fueron integrados sistemáticamente en el plan curricular de 1998. En este plan las obras obligatorias de las literaturas analizadas son Don Quijote (M. Cervantes), Canción del jinete o Romance sonámbulo (F. García Lorca) y Cien años de soledad (G. García Márquez). En la antología de la literatura mundial de Kos de 1971 (Pregled svetovne književnosti) ya se destaca a García Márquez como uno de los más importantes escritores de la época, así que en el mismo año ya aparece la traducción de Cien años de soledad. Entre las obras optativas del plan de 1998 podemos encontrar La casa de Bernarda Alba (F. García Lorca), Ficciones (J. L. Borges), la lírica de P. Neruda y la novela contemporánea Corazón tan blanco, de J. Marías, traducida al esloveno en 1997.

El plan curricular actual (2008) se compone de 21 módulos temáticos, de los cuales 4 de ellos incluyen obras literarias en español. Aumenta el número de los textos literarios optativos: Cantar del mio Cid, Lazarillo de Tormes, Pierre Menard, autor del Quijote (actualización de Don Quijote a manos de J. L. Borges) y Edipo y el enigma (J. L. Borges). Por primera vez se incluye también la poesía de O. Paz con Antes del comienzo. 


\begin{tabular}{|l|l|l|}
\hline Módulo temático & Textos obligatorios & Textos optativos \\
\hline $\begin{array}{l}\text { Literatura medieval en } \\
\text { Europa y Eslovenia }\end{array}$ & $/$ & Cantar del mio Cid \\
\hline Renacimiento & Cervantes: Don Qujiote & $\begin{array}{l}\text { Lazarillo de Tormes, } \\
\text { Borges: Pierre Menard, autor } \\
\text { del Quijote }\end{array}$ \\
\hline $\begin{array}{l}\text { Literatura mundial en la } \\
\text { primera mitad de siglo XX }\end{array}$ & $\begin{array}{l}\text { García Lorca: Canción del } \\
\text { jinete }\end{array}$ & Borges: Edipo y el enigma \\
\hline $\begin{array}{l}\text { Literatura mundial en la } \\
\text { segunda mitad de siglo XX }\end{array}$ & $\begin{array}{l}\text { Paz: Antes del comienzo o } \\
\text { Neruda: Surgen hombres; } \\
\text { Borges: El Aleph o } \\
\text { García Márquez: Cien años } \\
\text { de soledad }\end{array}$ & Marías: Corazón tan blanco \\
\hline
\end{tabular}

Tabla 1: Obras literarias en el plan curricular del esloveno actual (2008)

\begin{tabular}{|l|c|c|c|c|c|c|c|c|c|}
\hline \multirow{2}{*}{ Autor/obra } & \multicolumn{9}{|c|}{ Plan curricular } \\
\hline & 1945 & 1946 & 1947 & 1955 & 1975 & 1986 & 1992 & 1998 & 2008 \\
\hline M. Cervantes & $\sqrt{ }$ & $\sqrt{ }$ & $\sqrt{ }$ & $*$ & $\sqrt{ }$ & $\sqrt{ }$ & $\sqrt{ }$ & $\sqrt{ }$ & $\sqrt{ }$ \\
\hline P. Neruda & $\sqrt{ }$ & $\sqrt{ }$ & & & $\sqrt{ }$ & & & $\sqrt{ }$ & $\sqrt{ }$ \\
\hline F. García Lorca & & & & & & $\sqrt{ }$ & $\sqrt{ }$ & $\sqrt{ }$ & $\sqrt{ }$ \\
\hline J. L. Borges & & & & & & $\sqrt{ }$ & $\sqrt{ }$ & $\sqrt{ }$ & $\sqrt{ }$ \\
\hline G. García Márquez & & & & & & $\sqrt{ }$ & $\sqrt{ }$ & $\sqrt{ }$ & $\sqrt{ }$ \\
\hline J. Marías & & & & & & & & $\sqrt{ }$ & $\sqrt{ }$ \\
\hline P. Calderón de la Barca & $\sqrt{ }$ & $\sqrt{ }$ & & & & & & & \\
\hline V. Blasco Ibáñez & & $\sqrt{ }$ & & & & & & & \\
\hline Cantar del mio Cid & & & & & & & & & $\sqrt{ }$ \\
\hline Lazarillo de Tormes & & & & & & & & & $\sqrt{ }$ \\
\hline O. Paz & & & & & & & & & $\sqrt{ }$ \\
\hline
\end{tabular}

Tabla 2: Literatura española e hispanoamericana en los planes curriculares del esloveno desde 1945 


\section{La selección de literatura en español según los libros del alumno}

Los libros del alumno o libros de textos son las fuentes fundamentales que indirectamente organizan la enseñanza y están principalmente destinados a los estudiantes. En el ámbito de la enseñanza de la literatura los llamamos también libros de lectura. Conocemos dos tipos:

a) libros que en la selección de los textos corresponden al plan curricular (ej. J. Kos et al.: Svet književnosti 1-4) y

b) libros antológicos que aparte de los textos obligatorios según el plan curricular añaden una selección más amplia de los textos representativos (ej. D. Ambrož et al.: Branja 1-4) (Krakar Vogel, 2004: 142).

Los libros para el análisis fueron escogidos según la incorporación de la literatura mundial. Ya Jožef Beg (2013: 355) comprobó que se trata de 11 libros de alumnos que fueron certificados en diferentes períodos temporales ${ }^{10}$, y Fatur (1995) expuso que la mayoría tuvo mucha influencia en la enseñanza después de la segunda guerra mundial. Se estudian también los tres libros escolares certificados actuales para profundizar la situación actual.

Los libros de alumnos sufrieron muchos cambios didácticos durante el período que siguió a la segunda guerra mundial. Los primeros dos libros analizados, Sodobno berilo za višje razrede srednjib šol (1947-1949) y Slovenska čitanka (1945), no incluyen la literatura española e hispanoamericana. Por las tendencias políticas predominan los textos literarios rusos, yugoslavos y eslovenos, por lo cual no tuvieron influencia en la formación del canon escolar.

Los libros de lectura de los años 60 y 70 muestran una unión más fuerte con el canon occidental, por eso incluyen también textos literarios de las literaturas analizadas. Los tres manuales (Svetovna književnost (1962), Slovensko berilo (1971-1974) y Slovenski jezik (1977-1980)) ofrecen fragmentos o poemas enteros: romances, Don Quijote y poemas de F. García Lorca. Los primeros dos manuales incluyen también obras de teatro de P. Calderón de la Barca y poemas de Neruda. El libro del alumno Svetovna književnost ofrece el más amplio y extenso panorama de la literatura mundial hasta los años 50 y presenta también las características de los períodos y géneros literarios y las poéticas

10 En la enseñanza primaria y secundaria eslovena solo se pueden usar los manuales certificados por la Comisión de manuales del Ministerio de Educación a base de dos reseñas elaboradas por un profesor practicante y un experto en el tema (normalmente profesor universitario). Los manuales tienen que estar en concordancia con el plan curricular nacional. 
de los autores. Aparte de los fragmentos, el manual enumera la mayoría de los autores canónicos de la literatura española ${ }^{11}$. Los tres manuales terminan su repaso en los años 50 del siglo XX, por lo cual no ofrecen otra literatura hispanoamericana aparte de Neruda.

\begin{tabular}{|c|c|c|c|}
\hline & \multicolumn{3}{|c|}{ Libro del alumno } \\
\hline & $\begin{array}{l}\text { Svetovna književnost } \\
\text { (1962) }\end{array}$ & $\begin{array}{l}\text { Slovensko berilo } \\
(1971-1974)\end{array}$ & $\begin{array}{l}\text { Slovenski jezik } \\
\text { (1977-1980) }\end{array}$ \\
\hline Romance & $\begin{array}{l}\text { El reino perdido, La } \\
\text { conquista de Alhama }\end{array}$ & El reino perdido & Doncella guerrera \\
\hline $\begin{array}{l}\text { Miguel de } \\
\text { Cervantes }\end{array}$ & $\begin{array}{l}\text { Don Quijote, Novelas } \\
\text { ejemplares }\end{array}$ & Don Quijote & Don Quijote \\
\hline $\begin{array}{l}\text { Pedro } \\
\text { Calderón de la } \\
\text { Barca }\end{array}$ & El alcalde de Zalamea & El alcalde de Zalamea & / \\
\hline $\begin{array}{l}\text { Frederico } \\
\text { García } \\
\text { Lorca }\end{array}$ & $\begin{array}{l}\text { Canción del jinete, } \\
\text { Romance sonámbulo, } \\
\text { Llanto por Ignacio } \\
\text { Sánchez Mejías }\end{array}$ & $\begin{array}{l}\text { Canción del jinete, } \\
\text { Romance sonámbulo, } \\
\text { Llanto por Ignacio } \\
\text { Sánchez Mejías }\end{array}$ & El grito \\
\hline $\begin{array}{l}\text { Pablo } \\
\text { Neruda }\end{array}$ & $\begin{array}{l}\text { La muerte, Machu } \\
\text { Picchu }\end{array}$ & Machu Picchu & / \\
\hline
\end{tabular}

Tabla 3: Textos literarios españoles e hispanoamericanos en los libros del alumno de los años 60 y 70

En los años 80 y 9o, especialmente en la primera mitad del período, la literatura española e hispanoamericana no tuvo un papel destacadamente importante. En el primer libro del alumno Književnost figura solo un poema de García Lorca (La casada infiel), los autores hasta omitieron a Don Quijote. Se trata de un manual que pone las literaturas eslovena y mundial en una posición subordinada a la literatura yugoslava. Los objetivos de enseñanza fueron sometidos a los objetivos políticos (mantener el socialismo y sus valores) y consecuentemente predominan las literaturas eslovena y yugoslava. Según Božič (2010: 199), el manual Književnost tiene el porcentaje más alto de literatura yugoslava en toda la historia de este tipo de manuales. La selección de las obras literarias

11 Como ejemplo ponemos aquí las obras y los escritores que se mencionan en el primer libro que cubre los periodos hasta el Romanticismo: Cantar de mio Cid; poetas como Lope de Vega, Luis de Góngora, Garcilaso de la Vega y Luis de León; el libro de caballería Amadís de Gaula, Los siete libros de la Diana de Jorge de Montemayor, las novelas picarescas Lazarillo de Tormes y Guzman de Alfarache y dramaturgos como Juan De Encina, Juan de la Cueva, Lope de Vega y Tirso de Molina. 
de los manuales Berilo I-III (1987-1990) corresponde al plan curricular de 1986. Los poemas de García Lorca Canción del jinete y Romance sonámbulo se convierten en los poemas más representativos del autor y así se encuentran en todos los manuales futuros. Se incluye también una biografía corta del autor, los comentarios de sus obras, también de obras de teatro y un glosario de palabras desconocidas. A Borges se le presenta como un escritor intelectual que usa los motivos de la literatura, pero los datos y las explicaciones de estilo y procedimientos literarios son aclarados solo parcialmente, lo que dificulta a los alumnos entender su obra. Lo mismo sucede con los términos del realismo mágico y los representantes de la literatura hispanoamericana al tratar Cien años de soledad. Lamentablemente Berilo no ofrece preguntas o tareas conectadas con la lectura, lo que se muestra también en los capítulos que incluyen la literatura española o hispanoamericana. El libro del alumno actualizado (Berilo I-IV, 1993 y 1994) disminuyó la cantidad de textos literarios, sobre todo de origen yugoslavo, debido a la independización de Eslovenia, pero el campo de las literaturas en lengua castellana no sufre modificaciones en la selección, todo lo contrario, se amplían las explicaciones de los términos y las interpretaciones.

\begin{tabular}{|c|c|c|c|}
\hline & \multicolumn{3}{|l|}{ Libro del alumno } \\
\hline & $\begin{array}{l}\text { Književnost } \\
(1981-1982, \\
1983-1984)\end{array}$ & $\begin{array}{l}\text { Berilo } \\
(1987-1990)\end{array}$ & $\begin{array}{l}\text { Berilo } \\
(1993,1994)\end{array}$ \\
\hline $\begin{array}{l}\text { Miguel de } \\
\text { Cervantes }\end{array}$ & I & Don Quijote & Don Quijote \\
\hline $\begin{array}{l}\text { Frederico } \\
\text { García Lorca }\end{array}$ & La casada infiel & $\begin{array}{l}\text { Canción del jinete, } \\
\text { Romance sonámbulo }\end{array}$ & $\begin{array}{l}\text { Canción del jinete, } \\
\text { Romance sonámbulo }\end{array}$ \\
\hline $\begin{array}{l}\text { Gabriel García } \\
\text { Márquez }\end{array}$ & 1 & Cien años de soledad & Cien años de soledad \\
\hline $\begin{array}{l}\text { Jorge Luis } \\
\text { Borges }\end{array}$ & 1 & Ficciones - El fin & $\begin{array}{l}\text { Pierre Menard, autor } \\
\text { del Quijote }\end{array}$ \\
\hline
\end{tabular}

Tabla 4: Textos literarios españoles e hispanoamericanos en los libros del alumno de los años 80 y 90

Los años 90 traen novedades en la didáctica de la literatura, y por lo tanto también en los planes curriculares, al tiempo que se desarrolla el negocio editorial. Los tres libros del alumno certificados actualmente, Branja (20082010), Umetnost besede (2007-2010) y Svet književnosti (2009-2011), siguen las 
tendencias de los libros de alumnos modernos: tienen diseño atractivo, añaden materiales ilustrativos, posibilitan las clases interdisciplinarias y el desarrollo de competencias diversas. Además hacen referencia a las fuentes en la red con sus correspondientes enlaces y proporcionan información sobre otras obras artísticas relacionadas: películas, representaciones teatrales, etc. Branja es un libro antológico con una selección más amplia de textos, mientras que los otros dos siguen la selección del plan curricular.

Debido al carácter antológico, el manual Branja ofrece el número de textos literarios españoles e hispanoamericanos más alto. Es el único manual que incluye un soneto de Luis de Góngora e incluye más de dos textos (en caso de García Lorca cuatro) de un mismo autor. El número disminuye en la segunda edición (2008-2010) por las tendencias del nuevo plan curricular (2008). Los análisis e interpretaciones se profundizan con comparaciones con la literatura eslovena o la mundial de diferentes épocas literarias, las citas o las ideas filosóficas de autores y las opiniones de historiadores, críticos literarios u otros autores. Los libros de alumnos Svet književnosti y Umetnost besede incorporan los textos literarios que están determinados por el plan curricular. Los dos manuales ofrecen los mapas o las tablas de escritores en diferentes épocas, las informaciones contextuales y literarias, las conexiones con otras artes y las tareas para los alumnos. Los tres manuales difieren en la selección de los textos de un mismo autor y la variedad es la más alta con prosa corta de Borges ( $E l$ Aleph, La búsqueda de Averroes, La casa de Asterión) y poemas de García Lorca. El único manual que ofrece también la literatura contemporánea española es Umetnost besede que recomienda la lectura íntegra de Corazón tan blanco de J. Marías, solo en el DVD añadido como un texto optativo. La tabla 5 presenta la obras y los autores que incluyen los tres libros de alumno.

\begin{tabular}{|c|c|c|c|c|c|}
\hline & \multicolumn{5}{|c|}{ Libro del alumno } \\
\hline & $\begin{array}{l}\text { Branja } \\
(2000-2003)\end{array}$ & $\begin{array}{l}\text { Branja } \\
(2008-2010)\end{array}$ & $\begin{array}{l}\text { Svet } \\
\text { književnosti } \\
(2000-2003)\end{array}$ & $\begin{array}{l}\text { Svet } \\
\text { književnosti } \\
(2009-2011)\end{array}$ & $\begin{array}{l}\text { Umetnost } \\
\text { besede } \\
(2007-2010)\end{array}$ \\
\hline Romances & $\begin{array}{l}\text { Romance de } \\
\text { reino perdido; } \\
\text { Romance del } \\
\text { amor más } \\
\text { poderoso que } \\
\text { la muerte }\end{array}$ & $\begin{array}{l}\text { Romance del } \\
\text { amor más } \\
\text { poderoso que } \\
\text { la muerte }\end{array}$ & / & / & / \\
\hline $\begin{array}{l}\text { Novela } \\
\text { picaresca }\end{array}$ & $\begin{array}{l}\text { Lazarillo de } \\
\text { Tormes }\end{array}$ & $\begin{array}{l}\text { Lazarillo de } \\
\text { Tormes }\end{array}$ & / & l & / \\
\hline
\end{tabular}




\begin{tabular}{|c|c|c|c|c|c|}
\hline & \multicolumn{5}{|c|}{ Libro del alumno } \\
\hline & $\begin{array}{l}\text { Branja } \\
(2000-2003)\end{array}$ & $\begin{array}{l}\text { Branja } \\
(2008-2010)\end{array}$ & $\begin{array}{l}\text { Svet } \\
\text { književnosti } \\
(2000-2003)\end{array}$ & $\begin{array}{l}\text { Svet } \\
\text { književnosti } \\
(2009-2011)\end{array}$ & $\begin{array}{l}\text { Umetnost } \\
\text { besede } \\
\text { (2007-2010) }\end{array}$ \\
\hline $\begin{array}{l}\text { M. } \\
\text { Cervantes }\end{array}$ & $\begin{array}{l}\text { El ingenioso } \\
\text { hidalgo don } \\
\text { Quijote de la } \\
\text { Mancha }\end{array}$ & $\begin{array}{l}\text { El ingenioso } \\
\text { hidalgo don } \\
\text { Quijote de la } \\
\text { Mancha }\end{array}$ & $\begin{array}{l}\text { El ingenioso } \\
\text { hidalgo don } \\
\text { Quijote de la } \\
\text { Mancha }\end{array}$ & $\begin{array}{l}\text { El ingenioso } \\
\text { hidalgo don } \\
\text { Quijote de la } \\
\text { Mancha }\end{array}$ & $\begin{array}{l}\text { El ingenioso } \\
\text { hidalgo don } \\
\text { Quijote de la } \\
\text { Mancha }\end{array}$ \\
\hline $\begin{array}{l}\text { L. de } \\
\text { Góngora }\end{array}$ & $\begin{array}{l}\text { Soneto } \\
\text { (Mientras por } \\
\text { competir con } \\
\text { tu cabello) }\end{array}$ & / & / & / & / \\
\hline $\begin{array}{l}\text { F. García } \\
\text { Lorca }\end{array}$ & $\begin{array}{l}\text { Despedida, } \\
\text { Canción } \\
\text { del jinete, } \\
\text { Romance } \\
\text { sonámbulo, } \\
\text { La casada } \\
\text { infiel }\end{array}$ & $\begin{array}{l}\text { Despedida, } \\
\text { Canción } \\
\text { del jinete, } \\
\text { Romance } \\
\text { sonámbulo }\end{array}$ & $\begin{array}{l}\text { Canción } \\
\text { de jinete, } \\
\text { Romance } \\
\text { sonámbulo, } \\
\text { La casada } \\
\text { infiel }\end{array}$ & $\begin{array}{l}\text { Canción del } \\
\text { jinete }\end{array}$ & $\begin{array}{l}\text { El grito, } \\
\text { Canción } \\
\text { del jinete, } \\
\text { Romance } \\
\text { sonámbulo }\end{array}$ \\
\hline P. Neruda & $\begin{array}{l}\text { Para que tú } \\
\text { me oigas; } \\
\text { Canto } \\
\text { General. } \\
\text { Surgen } \\
\text { hombres }\end{array}$ & $\begin{array}{l}\text { Canto } \\
\text { General. } \\
\text { Surgen } \\
\text { hombres }\end{array}$ & / & $\begin{array}{l}\text { Surgen } \\
\text { hombres }\end{array}$ & $\begin{array}{l}\text { Surgen } \\
\text { hombres }\end{array}$ \\
\hline O. Paz & $\begin{array}{l}\text { Antes del } \\
\text { comienzo, } \\
\text { Decir, hacer }\end{array}$ & $\begin{array}{l}\text { Antes del } \\
\text { comienzo, } \\
\text { Decir, hacer }\end{array}$ & l & $\begin{array}{l}\text { Antes del } \\
\text { comienzo }\end{array}$ & $\begin{array}{l}\text { Piedra de } \\
\text { sol, Antes del } \\
\text { comienzo, La } \\
\text { revelación } \\
\text { poética, } \\
\text { Ejemplo }\end{array}$ \\
\hline $\begin{array}{l}\text { J. L. } \\
\text { Borges }\end{array}$ & $\begin{array}{l}\text { El libro de } \\
\text { arena }\end{array}$ & El Aleph & $\begin{array}{l}\text { La búsqueda } \\
\text { de Averroes }\end{array}$ & El Aleph & $\begin{array}{l}\text { La casa de } \\
\text { Asterión }\end{array}$ \\
\hline $\begin{array}{l}\text { G. García } \\
\text { Márquez }\end{array}$ & $\begin{array}{l}\text { Cien años de } \\
\text { soledad }\end{array}$ & $\begin{array}{l}\text { Cien años de } \\
\text { soledad }\end{array}$ & $\begin{array}{l}\text { Cien años de } \\
\text { soledad }\end{array}$ & $\begin{array}{l}\text { Cien años de } \\
\text { soledad }\end{array}$ & $\begin{array}{l}\text { Cien años de } \\
\text { soledad }\end{array}$ \\
\hline J. Marías & 1 & 1 & / & I & $\begin{array}{l}\text { Corazón tan } \\
\text { blanco }\end{array}$ \\
\hline
\end{tabular}

Tabla 5: Textos literarios españoles e hispanoamericanos en los libros del alumno actualmente certificados 


\section{Conclusión}

Los resultados del análisis muestran que al canon de la literatura mundial en el ámbito de los institutos eslovenos, según los planes curriculares, agregan a Cervantes con el Quijote y a Neruda con su lírica, aunque los libros del alumno no incluyen sus textos desde 1977 hasta 2000. García Lorca entra tarde en el plan curricular, en 1986, pero los libros de lectura ofrecen sus poemas ya desde los años 60 o desde el primer manual que ofrece la literatura española o hispanoamericana. El poeta español es parte del canon mundial establecido en el ámbito de los institutos eslovenos, en su mayoría representado con sus poemas Canción del jinete y Romance sonámbulo. Los textos de Borges y García Márquez están presentes desde el fin de los años 80 simultáneamente en los planes curriculares y en los libros de alumno. Calderón de la Barca (El alcalde de Zalamea) es el único autor del Siglo de Oro obligatorio, y aun este es omitido muy temprano, en el plan curricular de 1948, y su última aparición en libros de alumno se puede observar en los años 70. En el ámbito de la literatura más antigua se pueden notar nuevos énfasis en el Lazarillo de Tormes y en el Cantar del mio Cid, pero no todos los libros de lectura actuales los incluyen; así, por ejemplo, el Cantar del mio Cid no se puede encontrar en ninguno, porque según el plan curricular actual (2008) forma parte de la literatura como materia optativa. Blasco Ibáñez figura solo en el plan curricular de 1946 y no aparece en ninguno de los libros del alumno, lo que no sorprende, porque no lo podemos incluir en el canon establecido de la literatura mundial.

Los textos de la literatura española e hispanoamericana forman parte de los libros del alumno desde los años 6o. Antes, la selección de textos literarios escolares estuvo marcada por circunstancias sociopolíticas relacionadas con el socialismo, que en el campo de la literatura siempre priorizó el aspecto didáctico. El número de los representantes y obras de la literatura española e hispanoamericana aumenta con el tiempo cuya culminación la encontramos en el plan curricular actual por su peculiaridad de proponer el número más alto de textos recomendados u optativos.

La selección más extensa de las literaturas analizadas acerca de los manuales corresponde a la primera edición del libro Branja (2000-2003), que trata de seguir el canon occidental y ya ha rechazado las literaturas de la antigua $\mathrm{Yu}-$ goslavia y el fomento de los valores socialistas. Su segunda edición disminuyó el número de los textos literarios, lo que fue condicionado por el nuevo plan curricular y por las tendencias de renovación del canon literario que anuncia la integración de algunos textos literarios de países pequeños, de autoras y 
países periféricos. Los libros del alumno actualmente certificados ofrecen una presentación sólida y adaptada al alumno de la educación secundaria. No se notan distinciones en la selección de los textos literarios de un mismo autor, excepto en el caso de los textos de Borges.

Es necesario resaltar el hecho de que ningún libro del alumno o plan curricular ofrece literatura de autoras españolas o hispanoamericanas, lo que confirma también el análisis de Jožef Beg sobre la literatura mundial (2013). Las obras de diferentes autoras (ej. Mistral, Pizarnik, Laforet, Martín Gaite, Montero, Allende, etc.) son traducidas al esloveno, lo cual no es obstáculo para su incorporación a los libros de lectura. La falta se puede observar también en la literatura contemporánea, de la cual solo se incluye al escritor español J. Marías, mientras que la selección en el ámbito de la literatura hispanoamericana se concluye con el boom hispanoamericano. Jožef Beg (2013) expone que la incorporación de un autor a los libros de lectura en el ámbito esloveno está condicionada también por la posesión del premio Nobel, lo que no ha ocurrido con los casos de Juan Ramón Jiménez, Miguel Ángel Asturias, Camilo José Cela, Vicente Aleixandre, Gabriela Mistral y Mario Vargas Llosa. Entre otros resultados, este análisis confirma que los grupos que también resultan marginados del canon son las naciones pequeñas y la literatura juvenil.

Es de esperar que los resultados obtenidos en el presente análisis ayuden y conduzcan a repensar sobre una selección equilibrada de la literatura nacional eslovena y la literatura universal en la educación secundaria, aunque el objetivo de este análisis es solo la presencia de la literatura española e hispanoamericana y no la presencia de otras literaturas, ya que la comparación sobrepasaría el tamaño y los objetivos de este artículo. La reflexión sobre el desarrollo y el estado de las literaturas española e hispanoamericana es necesaria para las decisiones futuras en la formación del canon escolar. Los resultados del análisis son esenciales también como instrumento para profesores de español como lengua extranjera en los institutos que en sus clases tratan la literatura en la lengua original, y complementan los contenidos de clase de la asignatura Lengua y Literatura (impartida en esloveno) o preparan proyectos y clases interdisciplinarias.

Para nuevas propuestas en el ámbito de la literatura española e hispanoamericana se necesita la colaboración de expertos de diferentes áreas - eslovenistas, hispanistas y didácticos. Por lo tanto, concluimos este artículo con el deseo de que los profesores de esloveno y de español reflexionemos conjuntamente y tomemos cartas en la selección de la literatura española e hispanoamericana, ya 
que tenemos arte y parte en la enseñanza del mundo mágico de la literatura a los jóvenes.

\section{Bibliografía}

Božič, Z. (2010): Slovenska literatura v šoli in Prešeren. Ljubljana: Tangram; Ljubljana: Demat.

Božič, Z. (2017): «Avtorice v slovenskih srednješolskih berilih». En: Jezik in slovstvo, 62, 1, 33-43.

Cerrillo Torremocha, P. (2013): «Canon literario, canon escolar y canon oculto». En: Quaderns de Filologia. Estudis literaris, XVIII, 17-31.

Colomer, T. (2010): La didáctica de la literatura: temas y lineas de investigación e innovación. Alicante: Biblioteca Virtual Miguel de Cervantes.

Fatur, S. (1995): «Žlahtna konservativnost (Zapis ob tržaških slovenskih berilih)». En: Jezik in slovstvo, 40, 3-4, 136-139.

Jožef Beg, J. (2013): «Svetovna književnost v berilih za splošno srednješolsko izobraževanje po letu 1945». En: Marko Juvan (ed.), Svetovne književnosti in obrobja. Ljubljana: ZRC SAZU, 353-371.

Jožef Beg, J. (2015): «Vzgoja kultiviranega bralca kot najpomembnejši cilj pouka književnosti v gimnaziji». En: Jezik in slovstvo, 60, 3-4, 55-63.

Kalenić Ramšak, B. (2011a): «Recepcija književnosti v španskem jeziku: še vedno španska vas?̊». En: Simona Kranjc (ed.), Meddisciplinarnost $v$ slovenistiki. (Obdobja 30). Ljubljana: Znanstvena založba Filozofske fakultete, 233-239.

Kalenić Ramšak, B. (2011b): «La recepción eslovena de Cervantes». En: Visiones y revisiones cervantinas: actas selectas del VII Congreso Internacional de la Asociación de Cervantistas. Biblioteca Virtual Miguel de Cervantes, 411-420.

Klemenčič, E., Štremfel, U. (2011): Nacionalna in mednarodna perspektiva izobraževanja za državljanstvo v multikulturni družbi. Ljubljana: ZRC SAZU.

Kopckzyk, M. (2008): «Literarni kanon - politika - šola (k razpravi o tem, kaj sodi v šolski kanon na Poljskem)». En: Boža Krakar Vogel (ed.), Književnost $v$ izobraževanju - cilji, vsebine, metode. (Obdobja 25 - Metode in zvrsti). Ljubljana: Filozofska fakulteta, 337-348.

Krakar Vogel, B. (2004): Poglavja iz didaktike književnosti. Ljubljana: DZS. 
Krakar Vogel, B. (2010): «Sodobna slovenska književnost v gimnazijskem učbeniku Branja 1 kot spodbuda za branje literarne klasike». En: Alojzija Zupan Sosič (ed.), Sodobna slovenska književnost (1980-2010) (Obdobja 25). Ljubljana: Filozofska fakulteta, 137-143.

Pregelj, B. (2005): «Španska zlata doba v slovenskih prevodih». En: Prevajanje baročnib in klasicističnib besedil: 3o. prevajalski zbornik. Ljubljana: Društvo slovenskih književnih prevajalcev, 45-48.

Pregelj, B. (2006): «Ljubim te, zeleno, ljubim». En: Sodobnost, 70, 9-10, 1090-1100.

Pregelj, B. (2008): «Španska književnost v slovenskih srednješolskih učbenikih». En: Boža Krakar Vogel (ed.), Književnost vizobraževanju - cilji, vsebine, metode. (Obdobja 25 - Metode in zvrsti). Ljubljana: Filozofska fakulteta, 399-405.

Pregelj, B., Kozak, K. J. (2007): «Federico García Lorca pri Slovencih». En: Federico García Lorca, Zbrana dramska dela, 1898-1936. Ljubljana: ZAMIK, 549-558.

Šumrada, L. (2015): Recepcija Pabla Nerude na Slovenskem. Ljubljana: Filozofska fakulteta. Trabajo de diploma.

Žbogar, A. (2007): Kratka proza v literarni vedi in šolski praksi. Ljubljana: Zavod Republike Slovenije za šolstvo.

Žbogar, A. (2013): Iz didaktike slovenščine. Ljubljana: Zveza društev Slavistično društvo Slovenije.

Žbogar, A. (2015): «Gimnazijski pouk književnosti v luči prenove in posodobitve». En: Jezik in slovstvo, 60, 3-4, 115-122.

\section{Corpus de los planes curriculares analizados}

Cvetko, V. (1962): Gimnazija, gradivo za sestavo predmetnika in učnega načrta. Ljubljana: DZS, Zavod za napredek šolstva LRS Slovenije.

Cvetko, V. et al. (1964): Gimnazija, gradivo za sestavo predmetnika in učnega načrta. Ljubljana: DZS.

Kmecl, M. et al. (1997): Slovenščina, predmetni katalog - učni načrt, gimnazija. Ministrstvo za šolstvo in šport: http://eportal.mss.edus.si/msswww/ programi2001/prgrami/gimnazija/gimnazija/3sloven.htm.

Kodela, R. (ed.) (1986): Družboslovno-jezikovna dejavnost SR: vzgojno-izobraževalni program srednjega izobraževanja). Ljubljana: Zavod RS za šolstvo.

Kos, J. (1992): Slovenski jezik in književnost. Učni načrt za pouk književnosti v 1., 2., in 3. Razredu srednje šole: Delovno gradivo 1992/93. Ljubljana: Zavod RS za šolstvo in šport. 
Poznanovič Jezeršek, M. et al. (2008): Učni načrt za slovenščino: splošna, klasična, strokovna gimnazija. Ministrstvo za šolstvo in šport in Zavod RS za šolstvo: http://portal.mss.edus.si/msswww/programi2010/programi/media/pdf/ un_gimnazija/un_slovenscina_gimn.pdf.

VV. AA. (1945): Začasni učni načrt na gimnazijab in klasičnib gimnazijab Slovenije. Celje: DZS, Ministrstvo za prosveto NVS.

VV. AA. (1947/47): Sprememba k učnemu načrtu za šolsko leto 1946/1947. Ljubljana: DZS, Ministrstvo za prosveto LRS.

VV. AA. (1948): Učni načrt za gimnazije, nižje gimnazije in višje razrede sedemletke. Ljubljana: DZS, Ministrstvo za prosveto LRS.

VV. AA. (1955): Učni načrt: za višje razrede gimnaziji n klasičnih gimnazij: Začasni pravilnik o maturi. Ljubljana: DZS, Svet za prosveto in kulturo LRS.

VV. AA. (1975): Gimnazija. Predmetnik in učni načrt. Ljubljana: Zavod SR Slovenije za šolstvo.

Zakrajšek, S. et al. (1992): Gimnazijski program. Ljubljana: Zavod Republike Slovenije za šolstvo in šport.

\section{Corpus de los manuales analizados}

Ambrož, D. et al. (2000-2003): Branja 1-3. Berilo in učbenik za prvi letnik gimnazij ter štiriletnił strokovnib šol. Ljubljana: DZS.

Ambrož, D. et al. (2008-2010): Branja 1-3. Berilo in učbenik za prvi letnik gimnazij ter štiriletnib strokovnib šol. Ljubljana: DZS.

Bajec, A. et al. (1945): Slovenska čitanka I.-IV. Ljubljana: DZS.

Bohanec, F. et al. (eds.) (1971-1974): Slovensko berilo za prvi, drugi, tretji, četrti razred srednjib šol. Ljubljana, Državna založba Slovenije.

Bohanec, F. et al. (1983-1984): Književnost III., IV. Maribor: Obzorja.

Fatur, S. (1981-1982): Književnost I., II. Maribor: Obzorja.

Gregorač, V. (1977-1980): Slovenski jezik. Berilo z analizo, literarno zgodovino in teorijo. 1., 2., 3. 4., snopič. Ljubljana: DDU Univerzum.

Kos, J., Pirjevec, D., Mihelič, S. (eds.) (1962): Svetovna književnost. Izbrana dela in odlomki, 1. in 2. knjiga. Ljubljana: Mladinska knjiga.

Kos, J., Logar, T. (eds.) (1987): Berilo 1, 2, 3, 4. Maribor: Obzorja.

Kos, J., Logar, T. (eds.) (1993, 1994): Berilo 1., 2., 3., 4. Maribor: Obzorja.

Kos, J. et al. (2000-2003): Svet književnosti 1-3. Maribor: Obzorja.

Kos, J. et al. (2009-2011): Svet književnosti 1-3. Maribor: Obzorja. 
Lah, K. et al. (2007-2010): Umetnost besede. Berilo 1-3. Ljubljana: Mladinska knjiga.

Lah, K. et al. (2014): Umetnost besede. Berilo 1. Ljubljana: Mladinska knjiga.

VV. AA. (1947-1949): Sodobno berilo za višje razrede srednjib šol I.-III. in IV. zvezek. Ljubljana: DZS. 


\author{
Marjana Šifrar Kalan \\ University of Ljubljana
}

Lucija Šarc

Ljubljana

\title{
The Presence of Spanish and Hispanic American Literature in Slovenian secondary Schools since 1945
}

Keywords: Spanish literature, Hispanic American literature, Slovene secondary schools, syllabus, textbook of international literature, teaching literature

Traditionally Slovene secondary schools teach national and international literature as part of the study of Slovene. The article examines the presence and the selection of Spanish and Hispanic American literature in Slovene secondary schools between 1945 and 2017 , taking into account sociopolitical, cultural and didactic factors. The analysis is based on all syllabuses for Slovene during this period and all text books for literature used and edited since the end of the second world war in Slovenia. Therefore the role of literature written in Spanish is analysed for two different sociopolitical contexts: Yugoslavia and the independent Republic of Slovenia. The aim of the article is to find out whether the presence and the role of Spanish language literature in Spanish has increased or decreased during this period and which are the authors and literary works which 19-year-old Slovenes who complete grammar school and continue their studies at the university are/were acquainted with. The article enumerates all writers and texts in Spanish from the analysed documents and textbooks, identifies drawbacks in the selection of the literature and concludes that experts from different fields, teachers of Slovene, Spanish, experts in literature and didactics should work on a well-balanced selection of Spanish and Hispanic American literature within the teaching of world literature. 
Marjana Šifrar Kalan

Univerza v Ljubljani

Lucija Šarc

Ljubljana

\section{Prisotnost španske in hispanoameriške književnosti v slovenski gimnaziji od leta 1945}

Ključne besede: španska književnost, hispanoameriška književnost, gimnazija, učni načrt, učbeniški sestav, poučevanje književnosti

Tradicionalno se $\mathrm{v}$ slovenskih gimnazijah nacionalna in svetovna književnost poučuje pri pouku slovenščine. Članek preučuje prisotnost ter izbiro španske in hispanoameriške književnosti pri pouku slovenščine v slovenskih gimnazijah med letoma 1945 in 2017 , upoštevajoč socialnopolitične, kulturne in didaktične značilnosti. Izsledki temeljijo na analizi vseh učnih načrtov za slovenščino za to obdobje ter vseh učbeniških sestavov, ki so bili izdani in uporabljeni v Sloveniji v tem obdobju. Vloga literature v španskem jeziku je tako obravnavana $\mathrm{v}$ dveh različnih sociopolitičnih kontekstih: znotraj Jugoslavije in samostojne Republike Slovenije. Cilj članka je ugotoviti, ali se prisotnost in vloga te literature $\mathrm{z}$ leti povečuje ali zmanjšuje ter katere avtorje in literarna dela so poznali oziroma poznajo devetnajstletniki, ki končajo gimnazijo in nadaljujejo študij na univerzi. V članku so predstavljeni vsi pisci in literarna dela $\mathrm{v}$ španskem jeziku, ki se pojavijo v preučevanih dokumentih in učbeniških sestavih, po drugi strani pa so predstavljene pomanjkljivosti v izboru španske in hispanoameriške literature, katere uravnotežen izbor pri poučevanju svetovne književnosti bi bil mogoč s sodelovanjem strokovnjakov z različnih področij slovenistov, hispanistov ter strokovnjakov za literaturo in didaktiko. 